\section{The smart bird of the south}

\author{
The Adélie Penguin: Bellwether of \\ Climate Change \\ by David G. Ainley \\ Columbia University Press: 2002. 314 pp.
}

$\$ 59.50, \mathfrak{E} 42.50$

\section{Yvon Le Maho and David Grémillet}

Penguins fascinate humans. They appeal to kids and adults alike, they hop around on television and their images fill toy stores. They are charismatic creatures par excellence. But penguins also intrigue scientists because surprisingly little is known about these seabirds, especially about their lives far offshore. Take the Adélie penguin. This 'little man in evening dress' only became known to science on 21 January 1840, when the French explorer Jules-Sébastien-César Dumont D'Urville and his crew reached the Antarctic mainland. D'Urville's men landed on some rocks off what he named 'Terre Adélie' after his wife Adèle. A painting at the National Maritime Museum in Paris recalls this event, showing how the crew of the Astrolabe hurtled down an island, carrying away some penguins, which were later described as the inhabitants of the newly discovered land.

Over 160 years later, David Ainley's book reminds us that the Adélie penguin is not a trophy, nor a pleasant mascot, but a most astonishing bird and a key element of the fragile Antarctic ecosystem. Ainley has been researching Antarctic and Pacific seabirds for some 30 years, so he is certainly the right person to compile this book. He was one of the early pioneers of the idea of Antarctic food webs linking penguin population dynamics with large-scale climatic features. Ainley shows that Adélie penguins exploit

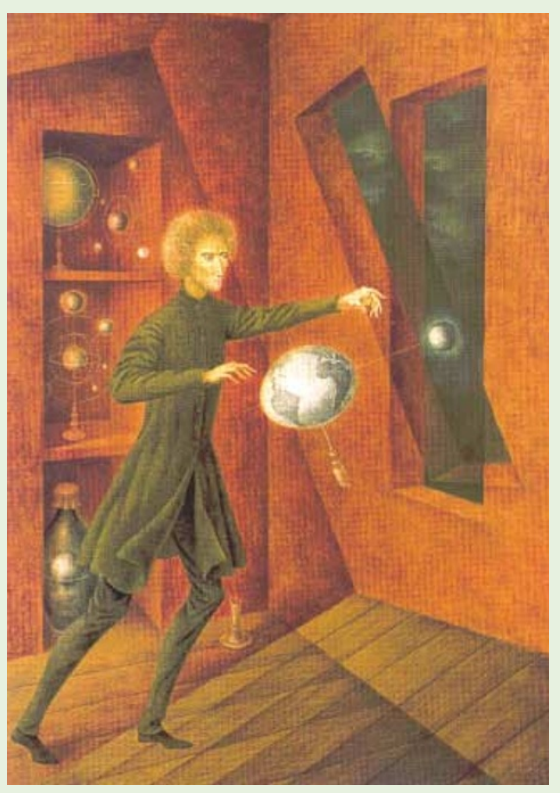

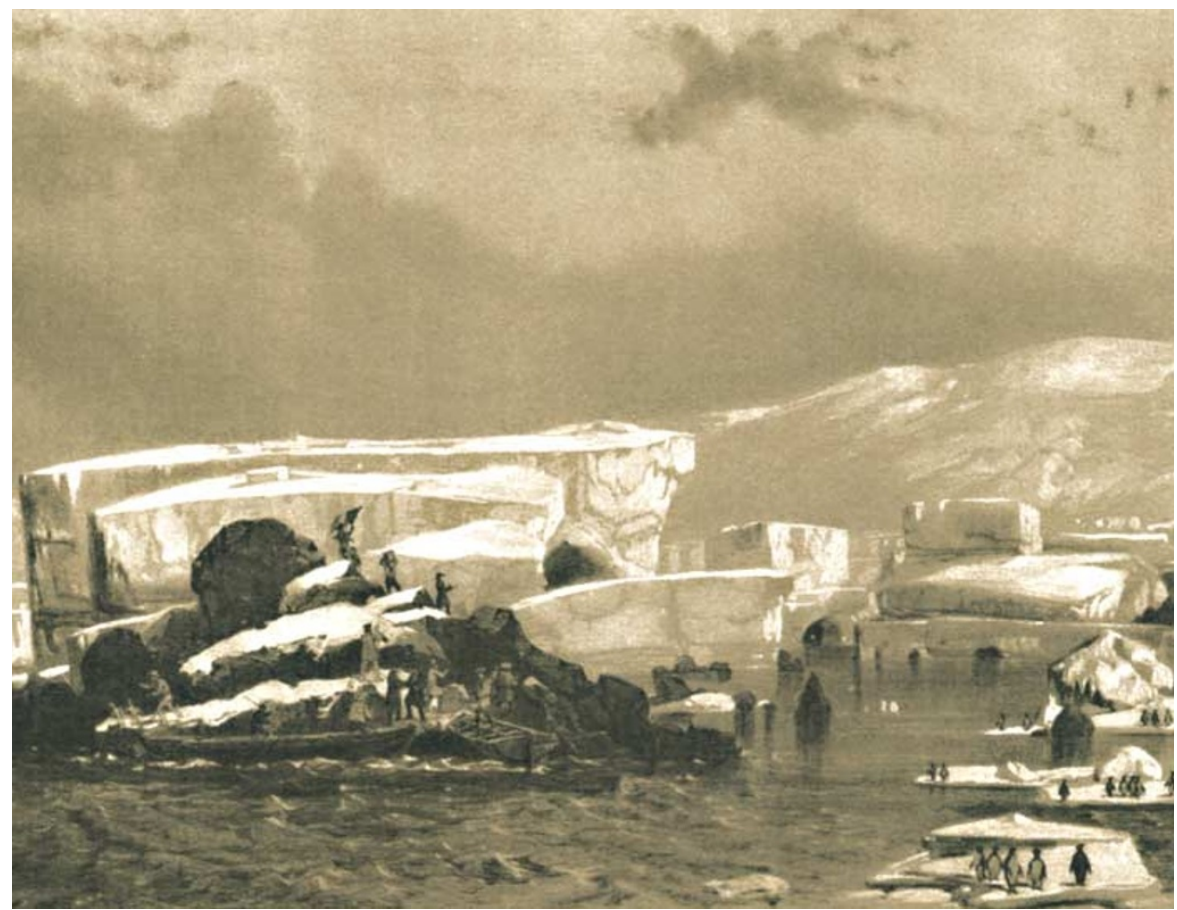

Voyage to a new land: this painting shows the discovery of the Adélie penguin on Terre Adélie in 1840.

the pack-ice zone better than any other seabird species, and that the extent of seaice cover around Antarctica conditions the lives of the 2.5 million Adélie penguins. He articulates his book around this idea, and this attractive volume addresses all of the major aspects of the bird's biology. It will be a marvellous source of information and inspiration for generations to come.

Ainley has been highly involved in a longterm study of the breeding biology of Adélie penguins at Cape Crozier in the Ross Sea. He presents the data set in detail, focusing on the breeding biology of birds from this area. Other crucial aspects, such as the bird's feeding behaviour, are unfortunately only briefly discussed. In that sense The Adélie Penguin

\section{A relative view of the Universe}

Spanish surrealist painter Remedios Varo created the metaphor shown here for Einstein's space-time Universe in 1963. The Phenomenon of Weightlessness, as it is called, is one of over 300 illustrations in Exploring the Invisible: Art, Science and the Spiritual (Princeton University Press, \$49.95) by the art historian Lynn Gamwell. The book, which is scholarly but highly readable, follows the history of the way that scientific thought and discovery has influenced art, particularly since the latter half of the nineteenth century. seems to comprise two different books. One is a detailed monograph on the breeding biology of the Adélie penguin in one particular location; the second is a brief yet attractive summary of the penguin's ecology in a global context. This leaves the reader to wonder whether the catchy subtitle was the author's choice, or rather reflects the marketing strategy of the publisher. In our view, Ainley's global perspective of Antarctic ecosystems would have been enriched by studies at more field sites, perhaps through collaborations outside the US community.

Beyond these minor shortcomings, Ainley consistently shows a rigorous, scientific approach. He is rightly concerned about the impact of scientific methods on the wellbeing of the animals. He was among the first to ask fundamental, pertinent questions about the impact of penguin ringing, for example. He was right from the start: penguin ringing might indeed reduce survival chances or breeding success, although the nature and the extent of the effect are still to be clarified.

Ainley had the tenacity and patience to run a long-term programme at Cape Crozier, gathering field data, year after year, in particularly difficult times when it was unfashionable to focus on anything other than molecular biology and biotechnology. Nowadays, links between the behaviour of marine top predators, the mechanics of marine food chains and global climate patterns are more than obvious. Suddenly, long-term studies of seabirds are sexy. As Ainley emphasizes in his book, scientists are now building rapidly on these immensely valuable background data. Using miniaturized electronic devices attached to the birds, 
they can explore the marine lives of Adélie penguins (these birds spend less than $10 \%$ of their lives on land) and further improve our understanding of oceanic ecosystems.

Yvon Le Maho and David Grémillet are at the Centre d'Ecologie et Physiologie Energétiques, UPR CNRS, 23 rue Becqerel, 67087 Strasbourg Cedex 2, France.

\section{Networks untangled}

\author{
Six Degrees: The Science of a \\ Connected Age \\ by Duncan J. Watts \\ W. W. Norton/Heinemann: 2003. 448 pp. \\ $\$ 27.95 / \mathfrak{E} 17.99$
}

\section{Lada Adamic}

Advances in computing over the past decade have not only improved the world's networks, they have made it easier for scientists to study networks, both new (the Internet) and old (metabolic and other biological networks that have been evolving for billions of years). The recent avalanche of research on networks was set off by Duncan Watts, who, while working on his $\mathrm{PhD}$ thesis with Steve Strogatz at Cornell University, wrote the seminal article "Collective dynamics of 'small-world' networks" (Nature 393, 440-442; 1998). Five years and hundreds of articles later, the research community is making progress in understanding the structure of networks. But working out how network structure affects dynamics, which was Watts' original interest, has proven to be a much harder problem. Undeterred, Watts has continued this vein of research, with several interesting and rewarding results. This book is a narrative of his research and of the many connections that have led him down this path.

\section{New in paperback}

Megawatts + Megatons: The Future of Nuclear Power and Nuclear Weapons by Richard Garwin and Georges Charpak University of Chicago Press, $\$ 20$

"We now have a book in which all aspects of the interaction between these two applications of nuclear energy are acknowledged and frankly examined, and the awesome global implications laid bare." Stuart Young,

Nature 414, 487-488 (2001).

\section{Our Cosmic Habitat}

by Martin Rees

Phoenix Press, £7.99

\section{A Thin Cosmic Rain}

by Michael W. Friedlander

Harvard University Press, \$17.95, £11.95, E18
Six Degrees follows closely on the heels of Albert-László Barabási's Linked and Mark Buchanan's Nexus (for a review of these two books, see Nature 418, 127-128; 2002). All three books cover quite a bit of common ground, including the major contributions to network research made by both Watts and Barabási. In addition, Six Degrees and Linked use many of the same examples to illustrate the role of networks. There is the groundbreaking experiment in the 1960s by Stanley Milgram showing that any two people in the United States (and probably the world) are connected to each other through a mere 'six degrees'. There are the observations that networks are important in the spread of computer viruses via the Internet, and the AIDS epidemic through sexual contacts. There is also the certainty that everything is connected: in 1996, the failure of a single transmission line in the US electrical grid caused major power outages across the western United States; and the 1997 currency-exchange crisis in Thailand was felt not only in Southeast Asia, but worldwide.

Six Degrees and Linked differ in their focus, however. Barabási tells a simple and convincing story: that networks in many systems arise through a rich-get-richer phenomenon, yielding many poorly connected nodes and a few hubs, or extremely well-connected nodes. These hubs affect properties of the network, such as susceptibility to computer-virus epidemics. Watts' book presents a broader view: that the distribution of connections among the nodes is just one of the factors that influence the dynamics of networks. In the context of social networks, some individuals may be better connected than others, but who we know also depends on who our friends know, and where we live and work, and this leads to a network property called 'clustering. Watts' original Nature article showed that networks can be clustered, but as long as there are a few random connections, the network is a 'small world', with only a few hops separating any two nodes.

But the existence of short paths does not, in itself, explain how people can find their targets. If you are trying to reach someone, but know only your friends, and some of your friend's friends, six degrees can seem quite distant. Watts has developed a mathematical model to show why individuals succeed in finding short paths simply by choosing for each link in the chain a friend who is most like the target. In addition to presenting a solution to the small-world problem, Watts has studied information cascades and the spread of disease in networks. The insights

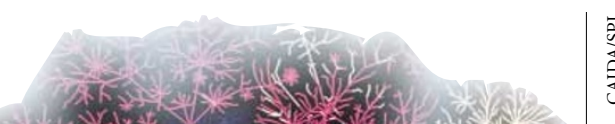

章 